\title{
A generalised failure envelope for undrained capacity of circular shallow foundations under general loading
}

\author{
C. VULPE* ${ }^{*}$ S. GOURVENEC* and M. POWER $\uparrow$
}

\begin{abstract}
This paper presents a generalised failure envelope for the prediction of the undrained capacity of circular shallow foundations under general vertical, horizontal and moment (VHM) loading. Uniaxial capacities and failure envelopes under combined loading are presented for shallow circular foundations over a practical range of embedment ratio and soil strength heterogeneity. An approximating expression is proposed to describe the shape of the normalised VHM failure envelope as a function of foundation embedment ratio, normalised soil strength heterogeneity index and vertical load mobilisation.
\end{abstract}

KEYWORDS: bearing capacity; footings/foundations; offshore engineering

ICE Publishing: all rights reserved

\section{NOTATION}

$A$

$D$

$d$

$d_{\mathrm{cV}}, d_{\mathrm{cH}}, d_{\mathrm{cM}}$

$E_{\mathrm{u}}$

$H$

$H_{\text {ult }}$

$k$

$M$

$M_{\text {ult }}$

$N_{\mathrm{cV}}, N_{\mathrm{cH}}, N_{\mathrm{cM}}$

$s_{\mathrm{u}}$

$s_{\text {um }}$

$V$

$V_{\text {ult }}$

$\gamma^{\prime}$ cross-sectional plan area of the foundation foundation diameter

skirt depth

depth factors

undrained Young's modulus

horizontal load

uniaxial horizontal capacity

undrained shear strength gradient

moment

uniaxial moment capacity

bearing capacity factors

undrained shear strength

undrained shear strength at the mudline vertical load

uniaxial vertical capacity

depth

effective unit weight

soil heterogeneity index

Poisson's ratio

\section{INTRODUCTION}

General loading of foundation systems may arise from the combined actions of self-weight, inclined or eccentrically applied dead loads, operational or environmental loads. The capacity of foundations under general loading is a fundamental problem of geotechnical engineering and the advantage of failure envelope methods that explicitly account for independent load components over classical bearing capacity is widely acknowledged (Roscoe \& Schofield, 1957; Butterfield \& Ticof, 1979; Gottardi \& Butterfield, 1993; Ukritchon et al., 1998; Martin \& Houlsby, 2001; Gourvenec \& Randolph, 2003; Gourvenec \& Barnett, 2011). Advantages of failure envelope methods over classical bearing capacity theory include

Manuscript received 12 February 2014; first decision 12 March 2014; accepted 14 July 2014.

Published online at www.geotechniqueletters.com on 19 August 2014.

${ }^{*}$ Centre for Offshore Foundation Systems \& ARC Centre of Excellence for Geotechnical Science and Engineering, University of Western Australia, Perth, WA, Australia

$\uparrow$ Fugro-TSM, Perth, WA 6000, Australia, formerly a student at University of Western Australia
- explicit consideration of $(H, M / D$, ) interaction as opposed to linear superposition of load inclination and load eccentricity

- coupling of the horizontal and moment degrees of freedom for embedded foundations as opposed to a depth factor, the latter in effect leading to isotropic expansion of the failure envelope

- concurrent consideration of foundation geometry, embedment and soil strength profile as opposed to the superposition of independent factors

- provision for uplift resistance for skirted foundations at low vertical loads as opposed to the assumption of 'liftoff' under overturning moment at vertical loads less than half the ultimate uniaxial capacity $\left(V / V_{\text {ult }} \leq 0 \cdot 5\right)$ implied by the effective area method (Meyerhof, 1953)

- an indication of the proximity to failure in terms of changes in individual load components as opposed to a reduction in vertical bearing pressure (Gourvenec \& Barnett, 2011).

The failure envelope approach is not new (Roscoe \& Schofield, 1957), and has been widely applied to bearing capacity problems (e.g. Butterfield \& Ticof, 1979; Nova \& Montrasio, 1991; Butterfield \& Gottardi, 1994; Martin \& Houlsby, 2001; Bransby \& Randolph, 1998; Ukritchon et al., 1998; Taiebat \& Carter, 2000; Gourvenec \& Randolph, 2003; Gourvenec, 2007a, 2007b; Bransby \& Yun, 2009; Gourvenec \& Barnett, 2011; Govoni et al., 2011; Zhang et al., 2011; Vulpe et al., 2013; Mana et al., 2013; Feng et al., 2014).

Previous investigations have addressed plane strain and three-dimensional (3D) conditions, surface and embedded foundations, and uniform and linearly increasing shear strength profiles, but not comprehensively for all combinations. A summary of published work on failure envelopes for the undrained capacity of shallow foundations under general loading is shown in Table 1 . Table 1 highlights the coverage and gaps in the knowledge base of undrained ultimate limit states under general vertical, horizontal and moment (VHM) loading for shallow foundations. A systematic study of embedded circular foundations across a range of soil strength heterogeneity is notably absent, and provided the motivation for this study.

This study addressed the undrained capacity of circular shallow foundations under general VHM loading. Expressions are presented to predict pure vertical, horizontal 


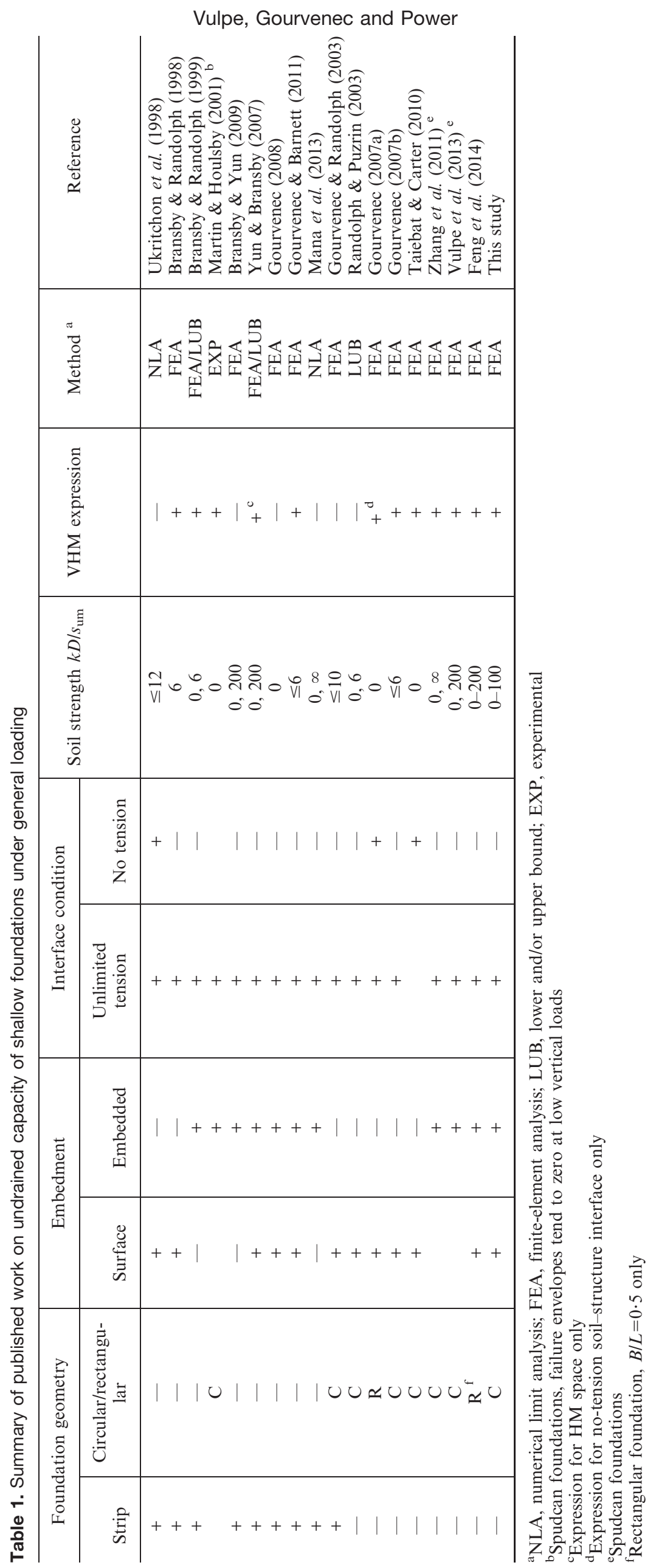


and moment capacity factors and 3D failure envelopes as a function of foundation embedment ratio, normalised soil strength heterogeneity index and vertical load mobilisation, derived from 3D finite-element analyses (FEA).

\section{FINITE-ELEMENT MODEL}

Three-dimensional small-strain analyses were used to model the undrained capacity of shallow circular foundations under general VHM loading. The FEA were carried out using the commercial finite-element software Abaqus (Dassault Systèmes, 2012). Sign conventions for this study follow the recommendations of Butterfield et al. (1997) and the notation used in this study is defined in Table 2.

\section{Model geometry and mesh}

Circular foundations with embedment depth to diameter ratios $d / D$ of 0 (surface), $0 \cdot 10,0 \cdot 25$ and $0 \cdot 50$ were considered. The foundations were wished-in-place (i.e. the installation process was not modelled). Zero-displacement boundaries of the mesh were located at a distance of $5 D$ to either side of the foundation centreline and $5 D$ below the free surface, sufficiently remote that the results were independent of the boundaries. Due to symmetry of the geometry and planar loading conditions, a semi-cylindrical section was modelled to optimise calculation efficiency. An example of the finite-element mesh used is shown in Fig. 1.

The soil was prescribed with first-order hexahedral hybrid elements. The foundation was modelled as a rigid body with a reference point for all loads and displacements prescribed on the axis of symmetry of the foundation at the base of the foundation (Fig. 2). The foundation was prescribed the same unit weight as the soil for geostatic equilibrium.

\section{Material properties}

The soil was modelled as a linear elastic-perfectly plastic material yielding according to the maximum shear stress, Tresca, failure criterion (i.e. $\tau_{\max }=s_{\mathrm{u}}$ ). Linearly increasing shear strength with depth was described by

$$
s_{\mathrm{u}}=s_{\mathrm{um}}+k z
$$

where $s_{\text {um }}$ is the shear strength at the mudline and $k$ is the shear strength gradient with depth $z$ (Fig. 2).

The degree of soil strength heterogeneity can be normalised with the foundation diameter $D$ through the dimensionless index

$$
\kappa=\frac{k D}{s_{\mathrm{um}}}
$$

Values of $\kappa$ of 0 (uniform shear strength with depth), 6, 20, 60 and 100 (essentially normally consolidated) were considered.

The soil was prescribed an undrained Young's modulus linearly increasing with depth with constant $E_{\mathrm{u}} / s_{\mathrm{u}}=500$, Poisson's ratio $v=0.499$ and effective unit weight $\gamma^{\prime}=6 \mathrm{kN} / \mathrm{m}^{3}$, which are realistic values for a soft marine clay. The undrained ultimate limit state of a shallow foundation is independent of the magnitude of the elastic properties and self-weight of the soil (the strain or displacement to ultimate limit state is affected but not the magnitude of ultimate limit state), such that the particular values selected, while realistic, are incidental. The foundation-soil interface over the embedded portion of the foundation was fully bonded (i.e. fully rough in shear with no separation permitted).

\section{Loading method}

Load and displacement control were used to apply the combined load paths to the foundation. Pure vertical (V), horizontal $(\mathrm{H})$ and moment $(\mathrm{M})$ capacity were identified from displacement-controlled probes applied to the reference point until a plastic plateau was observed in the loaddisplacement response. General VHM loading was achieved by applying a vertical load as a direct force, after which a constant ratio displacement probe of translation and rotation was applied to the reference point. Vertical load level was defined as a proportion of the uniaxial vertical capacity, $V_{\text {ult }}$, described by $v=V / V_{\text {ult }}$, where $v$ took values of $0,0 \cdot 50$ or $0 \cdot 75$.

\section{Validation}

Vertical bearing capacity factors for the surface and embedded circular foundations predicted from the FEA were compared with exact solutions for the surface foundations (Martin, 2003) and upper bound solutions for the embedded cases (Martin \& Randolph, 2001). Pure horizontal capacity of the surface foundation was compared with the theoretical solution for surface sliding $\left(H / A s_{\mathrm{u}}=1\right)$ and pure moment capacity was compared with a theoretical upper bound solution (Randolph \& Puzrin, 2003). A mesh refinement study determined the optimum mesh discretisation as a function of soil strength heterogeneity index. The mesh refinement consisted of gradually increasing the number of elements around the foundation where the failure mechanism developed until further refinement did not improve the result. In some cases, a pragmatic assessment was made to tolerate a numerical over-prediction if the improvement in result was minimal but the addition of more elements caused an excessive increase in run time. For uniform strength with depth $(\kappa=0)$, the optimum mesh contained 35000 elements, increasing to 50000 elements for the case of $\kappa=100$.

Vertical capacity of the surface foundation was accurately predicted for a range of soil strength heterogeneity, to within $1 \%$ of the theoretically exact solutions (Martin, 2003) and lower than the upper bound for the embedded foundation geometry (Martin \& Randolph, 2001). Pure horizontal capacity of the surface foundations was close to the theoretical solution for surface sliding $\left(H / A s_{\mathrm{u}}=1\right)$ for a low strength heterogeneity index but was over-estimated with increasing degree of soil strength heterogeneity due to shearing in a single band of elements at the foundation-soil

\begin{tabular}{|c|c|c|c|}
\hline & Vertical & Horizontal & Rotational \\
\hline $\begin{array}{l}\text { Displacement } \\
\text { Load } \\
\text { Pure uniaxial capacity } \\
\text { Maximum capacity } \\
\text { Normalised load }\end{array}$ & $\begin{array}{l}w \\
V \\
V_{\mathrm{ult}} \\
- \\
v=V / V_{\mathrm{ult}}\end{array}$ & $\begin{array}{l}u \\
H \\
H_{\mathrm{ult}} \\
H_{\mathrm{max}} \\
h=H / H_{\mathrm{ult}}\end{array}$ & $\begin{array}{l}\theta \\
M \\
M_{\mathrm{ult}} \\
M_{\mathrm{max}} \\
m=M / M_{\mathrm{ult}}\end{array}$ \\
\hline
\end{tabular}

Table 2. Definition of notation 


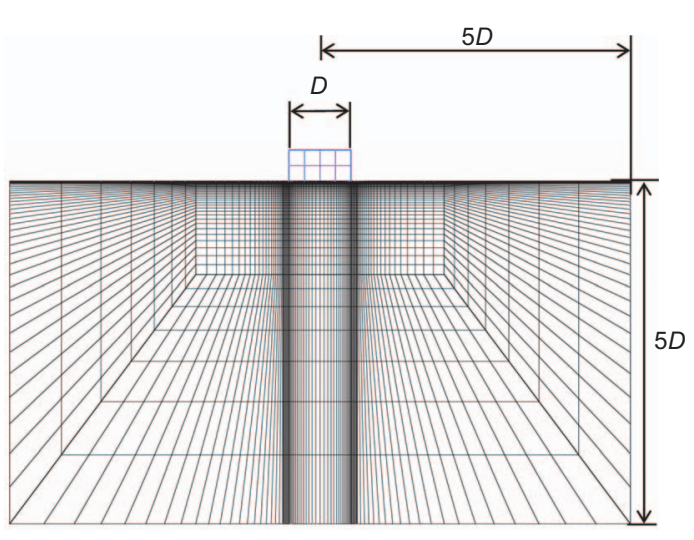

Fig. 1. Example of finite-element mesh $(d / D=0)$

interface (up to $10 \%$ for $\kappa=100$ ). Moment capacity was slightly over-predicted compared with a theoretical upper bound solution (Randolph \& Puzrin, 2003), by up to $10 \%$, due to representation of a circular scoop failure mechanism with hexahedral elements.

\section{RESULTS}

Pure vertical, horizontal and moment capacities (i.e. in the absence of other load components and referred to herein as uniaxial capacity), defined by $V_{\text {ult }}, H_{\text {ult }}$ and $M_{\text {ult }}$, and combined vertical, horizontal and moment capacities of circular foundations with varying embedment ratio $(d / D)$ and heterogeneity index $\left(\kappa=k D / s_{\text {um }}\right)$ were quantified through over 1000 3D FEA. Capacity was defined as the mobilised resistance at which continued deformation occurred with no further increase in load (i.e. when the material response exhibited a plastic plateau). The results are presented through simple approximating formulae, enabling prediction of generalised failure envelopes for the extensive range of conditions considered.

\section{Uniaxial capacity}

It is convenient to consider the predicted uniaxial capacity in terms of depth factors $d_{\mathrm{cV}}, d_{\mathrm{cH}}$ and $d_{\mathrm{cM}}$, defined for a given degree of shear strength heterogeneity $\kappa=k D / s_{\text {um }}$. The depth factors are given by

$$
d_{\mathrm{cV}}=\frac{N_{\mathrm{cV}(d / D, \kappa)}}{N_{\mathrm{cV}(d / D=0, \kappa)}}
$$

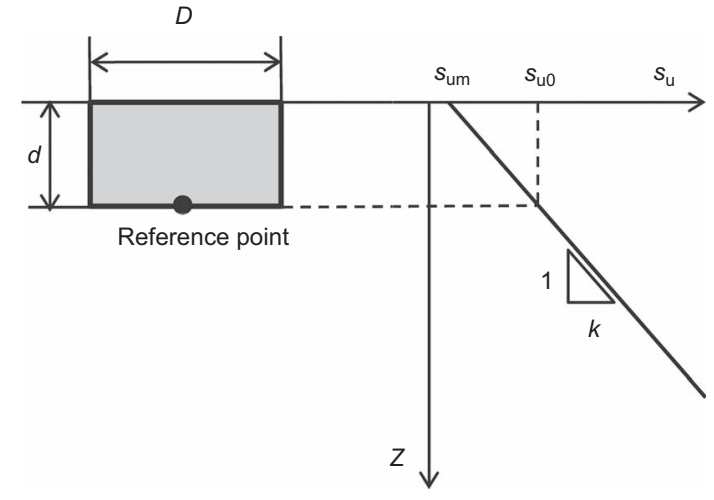

Fig. 2. Definition of notation for foundation geometry, reference point and soil strength profile for vertical bearing capacity

$$
d_{\mathrm{cH}}=\frac{N_{\mathrm{cH}(d / D, \kappa)}}{N_{\mathrm{cH}(d / D=0, \kappa)}}
$$

for horizontal capacity and

$$
d_{c M}=\frac{N_{\mathrm{cM}(d / D, \kappa)}}{N_{\mathrm{cM}(d / D=0, \kappa)}}
$$

for moment capacity. $N_{\mathrm{cV}}, N_{\mathrm{cH}}$ and $N_{\mathrm{cM}}$ are the capacity factors defined by

$$
\begin{aligned}
& N_{\mathrm{cV}}=\frac{V_{\mathrm{ult}}}{A s_{\mathrm{u} 0}} \\
& N_{\mathrm{cH}}=\frac{H_{\mathrm{ult}}}{A s_{\mathrm{u} 0}} \\
& N_{\mathrm{cM}}=\frac{M_{\mathrm{ult}}}{A D s_{\mathrm{u} 0}}
\end{aligned}
$$

in which $V_{\text {ult }}, H_{\text {ult }}$ and $M_{\text {ult }}$ are the pure uniaxial capacities in the absence of other loading or restraint, $A$ is the

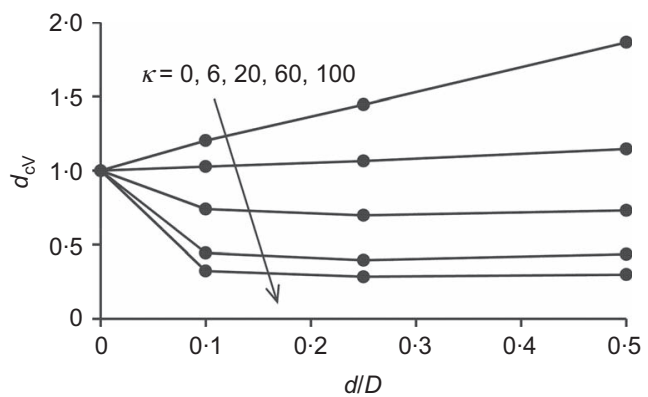

(a)

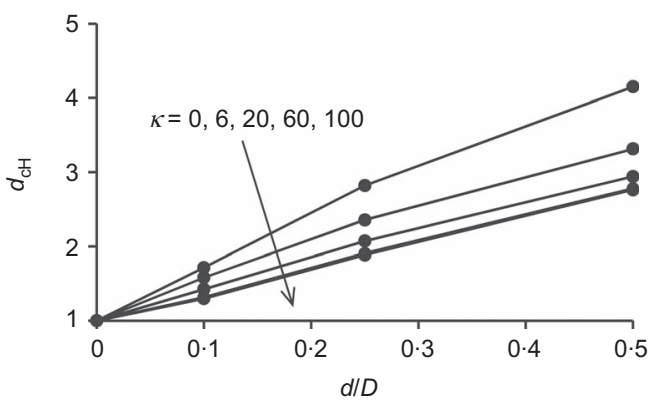

(b)

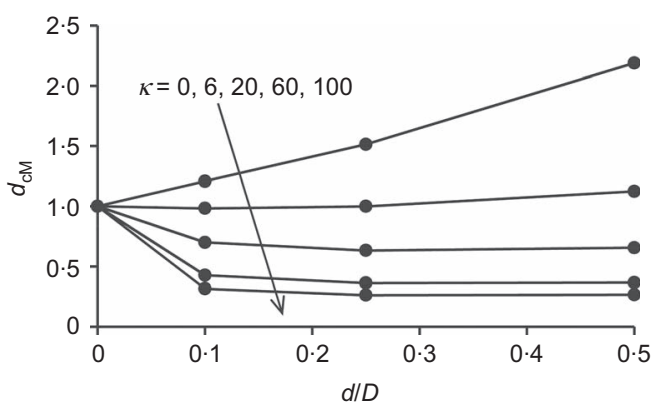

(c)

Fig. 3. Proposed depth factors for uniaxial loading: (a) vertical capacity; (b) horizontal capacity; (c) moment capacity 
Table 3. Depth factors for uniaxial vertical, horizontal and moment capacity; $d_{\mathrm{c}}=N_{\mathrm{c}(d / D, \kappa)} / N_{\mathrm{c}(d / D=0, \kappa)}$

\begin{tabular}{|c|c|c|c|c|}
\hline$d / D$ & $\kappa=k D / s_{\mathrm{um}}$ & $d_{\mathrm{cV}}$ & $d_{\mathrm{cH}}$ & $d_{\mathrm{cM}}$ \\
\hline 0 & 0 & 1 & 1 & 1 \\
\hline 0 & 6 & 1 & 1 & 1 \\
\hline 0 & 20 & 1 & 1 & 1 \\
\hline 0 & 60 & 1 & 1 & 1 \\
\hline 0 & 100 & 1 & 1 & 1 \\
\hline $0 \cdot 10$ & 0 & $1 \cdot 20$ & 1.72 & $1 \cdot 21$ \\
\hline $0 \cdot 10$ & 6 & 1.03 & $1 \cdot 58$ & $0 \cdot 98$ \\
\hline $0 \cdot 10$ & 20 & $0 \cdot 74$ & 1.42 & $0 \cdot 70$ \\
\hline $0 \cdot 10$ & 60 & $0 \cdot 44$ & $1 \cdot 32$ & 0.43 \\
\hline $0 \cdot 10$ & 100 & $0 \cdot 32$ & $1 \cdot 30$ & $0 \cdot 32$ \\
\hline $0 \cdot 25$ & 0 & $1 \cdot 45$ & $2 \cdot 82$ & $1 \cdot 51$ \\
\hline $0 \cdot 25$ & 6 & $1 \cdot 06$ & $2 \cdot 36$ & $1 \cdot 00$ \\
\hline $0 \cdot 25$ & 20 & $0 \cdot 70$ & $2 \cdot 07$ & 0.63 \\
\hline $0 \cdot 25$ & 60 & $0 \cdot 40$ & 1.91 & $0 \cdot 36$ \\
\hline $0 \cdot 25$ & 100 & $0 \cdot 28$ & $1 \cdot 89$ & $0 \cdot 26$ \\
\hline $0 \cdot 50$ & 0 & 1.87 & $4 \cdot 15$ & $2 \cdot 19$ \\
\hline $0 \cdot 50$ & 6 & $1 \cdot 15$ & $3 \cdot 31$ & $1 \cdot 13$ \\
\hline $0 \cdot 50$ & 20 & 0.73 & $2 \cdot 94$ & 0.66 \\
\hline $0 \cdot 50$ & 60 & $0 \cdot 44$ & $2 \cdot 78$ & 0.37 \\
\hline $0 \cdot 50$ & 100 & $0 \cdot 30$ & $2 \cdot 76$ & $0 \cdot 27$ \\
\hline
\end{tabular}

Table 4. Uniaxial capacity factors

\begin{tabular}{|c|c|c|c|c|}
\hline$d / D$ & $\kappa=k D / s_{\mathrm{um}}$ & $N_{\mathrm{cV}}$ & $N_{\mathrm{cH}}$ & $N_{\mathrm{cM}}$ \\
\hline 0 & 0 & $6 \cdot 05$ & 1 & 0.67 \\
\hline 0 & 6 & $9 \cdot 85$ & 1 & $1 \cdot 19$ \\
\hline 0 & 20 & $15 \cdot 48$ & 1 & 1.92 \\
\hline 0 & 60 & $27 \cdot 69$ & 1 & 3.49 \\
\hline 0 & 100 & $37 \cdot 88$ & 1 & $4 \cdot 77$ \\
\hline $0 \cdot 10$ & 0 & $7 \cdot 28$ & $1 \cdot 72$ & $0 \cdot 81$ \\
\hline $0 \cdot 10$ & 6 & $10 \cdot 11$ & $1 \cdot 58$ & $1 \cdot 17$ \\
\hline $0 \cdot 10$ & 20 & $11 \cdot 46$ & 1.42 & $1 \cdot 35$ \\
\hline $0 \cdot 10$ & 60 & $12 \cdot 30$ & $1 \cdot 32$ & 1.49 \\
\hline $0 \cdot 10$ & 100 & $12 \cdot 25$ & $1 \cdot 30$ & $1 \cdot 50$ \\
\hline $0 \cdot 25$ & 0 & $8 \cdot 75$ & $2 \cdot 82$ & $1 \cdot 01$ \\
\hline $0 \cdot 25$ & 6 & $10 \cdot 48$ & $2 \cdot 36$ & $1 \cdot 19$ \\
\hline $0 \cdot 25$ & 20 & $10 \cdot 81$ & $2 \cdot 07$ & $1 \cdot 22$ \\
\hline $0 \cdot 25$ & 60 & $10 \cdot 97$ & 1.91 & $1 \cdot 26$ \\
\hline $0 \cdot 25$ & 100 & $10 \cdot 78$ & 1.89 & $1 \cdot 25$ \\
\hline $0 \cdot 50$ & 0 & $11 \cdot 29$ & $4 \cdot 15$ & 1.47 \\
\hline $0 \cdot 50$ & 6 & $11 \cdot 29$ & $3 \cdot 31$ & $1 \cdot 34$ \\
\hline $0 \cdot 50$ & 20 & $11 \cdot 31$ & $2 \cdot 94$ & $1 \cdot 26$ \\
\hline $0 \cdot 50$ & 60 & $12 \cdot 07$ & $2 \cdot 78$ & $1 \cdot 28$ \\
\hline $0 \cdot 50$ & 100 & $11 \cdot 31$ & $2 \cdot 76$ & $1 \cdot 27$ \\
\hline
\end{tabular}

cross-sectional plan area of the foundation, $D$ is the foundation diameter and $s_{\mathrm{u} 0}$ is the undrained shear strength at foundation level, $s_{\mathrm{u} 0}=s_{\mathrm{um}}+k d$.

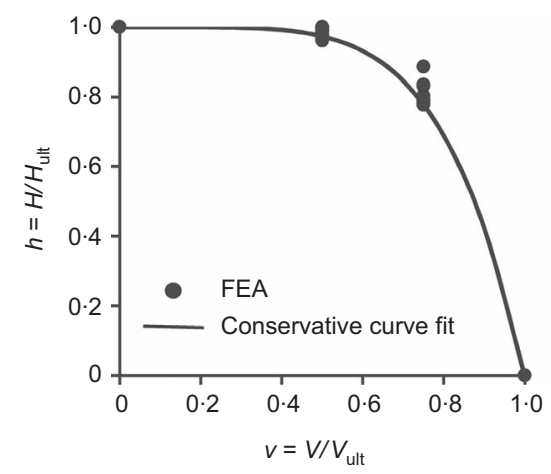

The vertical bearing capacity factor $N_{\mathrm{cV}(d / D=0, \kappa)}$ for a surface circular foundation (i.e. $d / D=0$ ) can be defined as a function of soil strength heterogeneity index $\kappa$ from

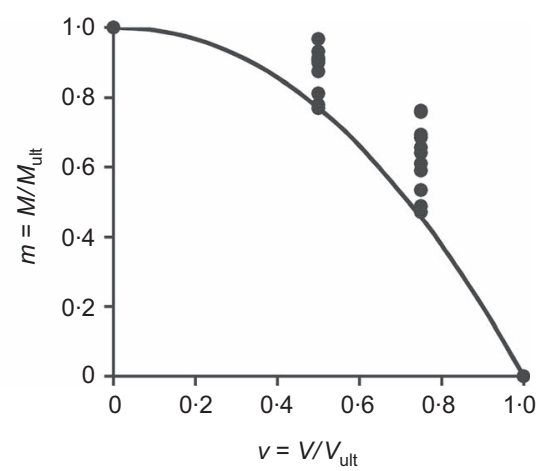

Fig. 4. Definition of lower limit to normalised vh and vm interactions over range of $d / D$ and $\kappa$ 


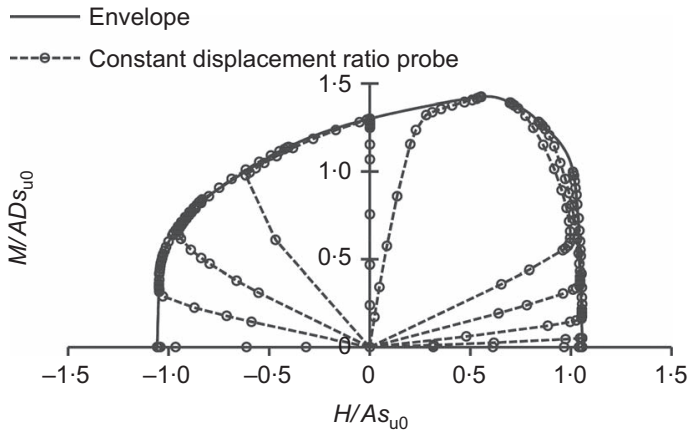

Fig. 5. Example of failure envelope using probe tests from FEA $(d / D=0, \kappa=6, V=0)$

available exact analytical solutions for a limited range of $\kappa$ (Houlsby \& Wroth, 1983), from numerical solutions (Gourvenec \& Mana, 2011) or with the numerical limit analysis freeware ABC (Martin, 2003). The various sources result in a similar relationship, which can be approximated through

$$
F_{\mathrm{V}}=\frac{N_{\mathrm{cV}(d / D=0, \kappa)}}{N_{\mathrm{cV}(d / D=0, \kappa=0)}}=1+(0 \cdot 09 \kappa)^{0 \cdot 76}
$$

where $N_{\mathrm{cV}(d / D=0, \kappa=0)}=6 \cdot 05$, the exact solution for a rough circular foundation on Tresca material (Cox et al., 1961).

$N_{\mathrm{cH}(d / D=0, \kappa)}=1$ irrespective of the soil heterogeneity index since the pure horizontal load capacity of a surface foundation is governed by the mudline shear strength for cases of uniform or increasing shear strength with depth.

$N_{\mathrm{cM}(d / D=0, \kappa)}$ can be defined as a function of soil strength heterogeneity coefficient from the FEA solutions as

$$
F_{\mathrm{M}}=\frac{N_{\mathrm{cM}(d / D=0, \kappa)}}{N_{\mathrm{cM}(d / D=0, \kappa=0)}}=1+0 \cdot 21 \kappa^{0 \cdot 74}
$$

where $N_{\mathrm{cM}(d / D=0, \kappa=0)}=0 \cdot 67$, from an upper bound solution (Randolph \& Puzrin, 2003).

The depth factors for pure vertical, horizontal and moment capacity of circular foundations with embedment ratio $0 \leq d l D \leq 0.50$ and soil shear strength heterogeneity index $0 \leq \kappa \leq 100$ are shown in Fig. 3 and summarised in Table 3. Uniaxial capacity factors derived from Table 3 and equations (3)-(10) are summarised in Table 4 to allow for direct interpolation of uniaxial ultimate limit states $V_{\text {ult }}$, $H_{\text {ult }}$ and $M_{\text {ult }}$.

\section{Combined vertical and horizontal load (VH) and vertical load and moment (VM) capacity}

Ultimate limit states under combined vertical and horizontal load and vertical load and moment are shown in Fig. 4 for the range of embedment ratios and soil strength heterogeneity considered in normalised vh and vm space, where $v=V / V_{\text {ult }}, h=H / H_{\text {ult }}$ and $m=M / M_{\text {ult }}$. A power law expression is used to define a lower limit of normalised vh and $\mathrm{vm}$ interaction; that is, the FE results for all embedment ratios and degrees of soil strength heterogeneity fall outside the fitted curve.

The normalised failure envelopes in vh space are closely banded, irrespective of the foundation embedment ratio or the soil shear strength heterogeneity index. The distribution of failure envelopes in normalised vm space is more diverse but shows no clear trend for grouping by embedment ratio or shear strength heterogeneity. Conservative fits to the vh and vm interactions are given by the power laws

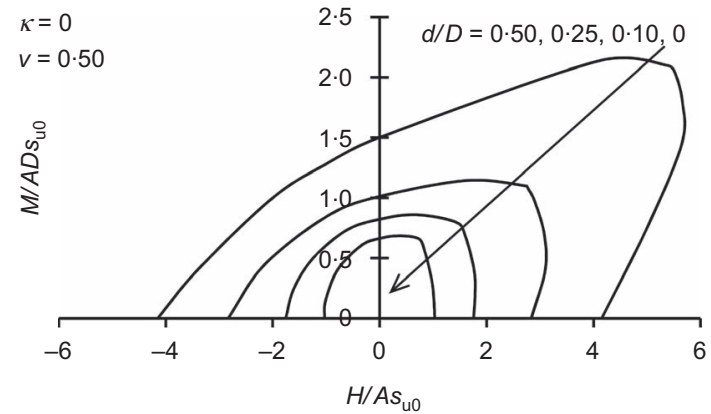

(a)

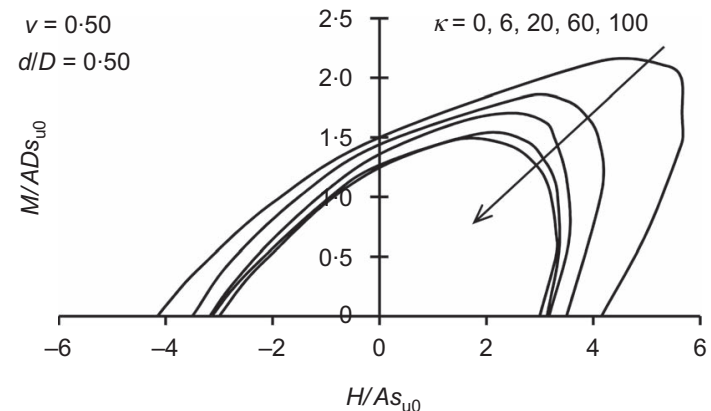

(b)

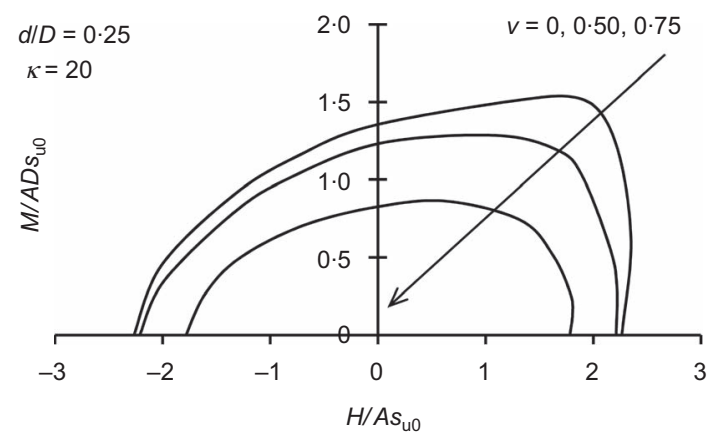

(c)

Fig. 6. Effect on shape and size of VHM failure envelopes of varying (a) foundation embedment ratio $d / D$, (b) soil strength heterogeneity index, $\kappa=k D / s_{\mathrm{um}}$ and (c) vertical load mobilisation $v=V / V_{\text {ult }}$

$$
h^{*}=1-v^{q}
$$

where $q=4.69$ and

$$
m^{*}=1-v^{p}
$$

in which $p=2 \cdot 12$.

The expressions $h^{*}$ and $m^{*}$ are functions used to describe the interactions in vh and vm space and determine the limiting horizontal or moment load in conjunction with a known applied vertical load. Inference of displacements at failure through the principle of normality should not be applied to the bounding surfaces described by equations (11) and (12) since they simply represent a lower limit to a range of observed results for a range of boundary conditions, rather than the precise shape of a particular failure envelope for a given set of boundary conditions. A failure envelope observing normality would be expected to exhibit zero change of gradient across the $H=0$ or $M=0$ axes.

Vertical, horizontal and moment (VHM) capacity Failure envelopes were constructed in HM load space by interpolating between individual $\mathrm{HD} / \mathrm{M}$ load paths resulting 
A generalised failure envelope for undrained capacity of circular shallow foundations under general loading 193
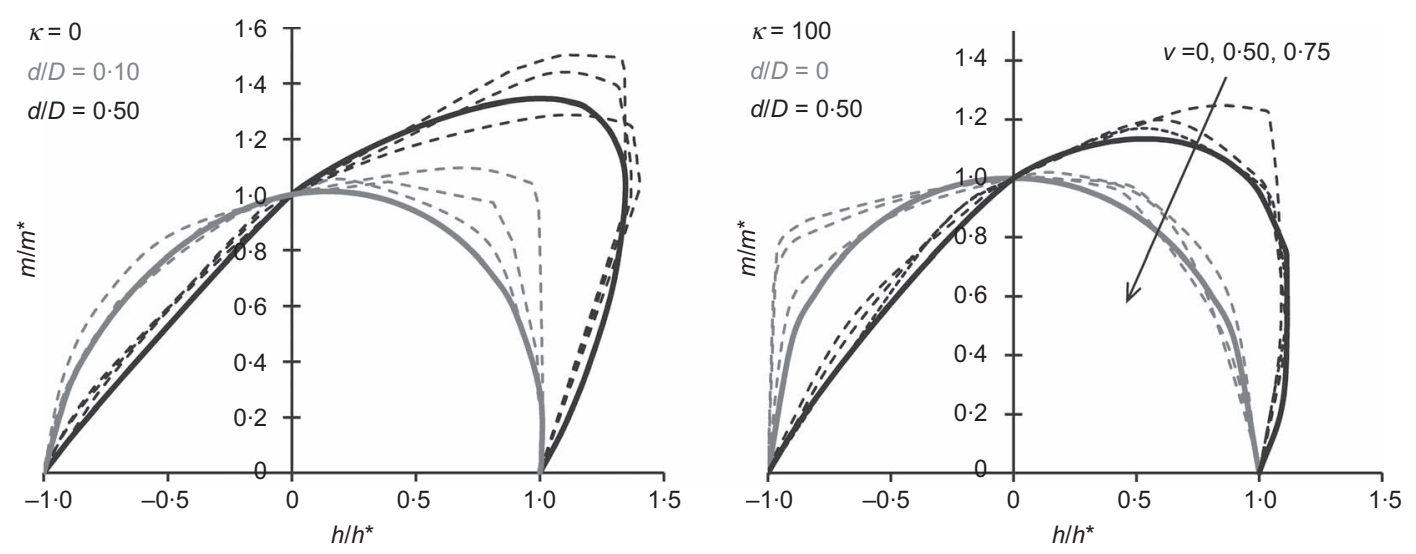

Fig. 7. Comparison of selected failure envelopes predicted by FEA (broken lines) and approximating expression (solid lines) (equation (13)); applicable to all levels of vertical load mobilisation $V / V_{\text {ult }}$

Table 5. Fitting parameters for approximating expression for VHM envelope for vertical load mobilisation $0 \leq V / V_{\text {ult }} \leq 1$

\begin{tabular}{|c|c|c|c|c|c|c|c|c|}
\hline \multirow{3}{*}{$\kappa$} & \multicolumn{4}{|c|}{$\alpha$} & \multicolumn{4}{|c|}{$\beta$} \\
\hline & \multicolumn{4}{|c|}{$d / D$} & \multicolumn{4}{|c|}{$d / D$} \\
\hline & 0 & $0 \cdot 10$ & $0 \cdot 25$ & $0 \cdot 50$ & 0 & $0 \cdot 10$ & $0 \cdot 25$ & $0 \cdot 50$ \\
\hline $\begin{array}{r}0 \\
6 \\
20 \\
60 \\
100\end{array}$ & $\begin{array}{l}1 \cdot 63 \\
2 \cdot 00 \\
2 \cdot 46 \\
2 \cdot 89 \\
3 \cdot 12\end{array}$ & $\begin{array}{l}1 \cdot 93 \\
1 \cdot 85 \\
2 \cdot 09 \\
2 \cdot 12 \\
2 \cdot 05\end{array}$ & $\begin{array}{l}2 \cdot 16 \\
1 \cdot 94 \\
1 \cdot 90 \\
1 \cdot 99 \\
2 \cdot 00\end{array}$ & $\begin{array}{l}1 \cdot 61 \\
1 \cdot 76 \\
1 \cdot 99 \\
2 \cdot 02 \\
1.65\end{array}$ & $\begin{array}{r}-0 \cdot 05 \\
0 \cdot 06 \\
-0 \cdot 01 \\
0 \cdot 13 \\
0 \cdot 13\end{array}$ & $\begin{array}{r}-0 \cdot 16 \\
-0 \cdot 10 \\
-0 \cdot 02 \\
0 \cdot 02 \\
0 \cdot 00\end{array}$ & $\begin{array}{l}-0 \cdot 44 \\
-0 \cdot 27 \\
-0 \cdot 21 \\
-0 \cdot 24 \\
-0 \cdot 22\end{array}$ & $\begin{array}{l}-0.60 \\
-0.55 \\
-0.48 \\
-0.46 \\
-0.48\end{array}$ \\
\hline
\end{tabular}

Table 6. Values of $h_{\text {max }} / h^{\star}$ for vertical load mobilisation $0 \leq V / V_{\text {ult }} \leq 1$

\begin{tabular}{l|c|c|c|c|c}
\hline \multirow{2}{*}{$d / D$} & \multicolumn{5}{|c}{$\kappa$} \\
\cline { 2 - 6 } & 0 & 6 & 20 & 60 & 100 \\
\hline 0 & 1 & 1 & 1 & 1 & 1 \\
$0 \cdot 10$ & 1 & 1 & 1 & 1 & 1 \\
$0 \cdot 25$ & $1 \cdot 09$ & $1 \cdot 02$ & $1 \cdot 01$ & $1 \cdot 11$ & $1 \cdot 11$ \\
$0 \cdot 50$ & $1 \cdot 35$ & $1 \cdot 15$ & & 1 & 1 \\
\hline
\end{tabular}

Table 7. Fitting parameters for approximating expression for VHM envelope for limited vertical load mobilisation $V / V_{\text {ult }} \leq 0 \cdot 50$

\begin{tabular}{|c|c|c|c|c|c|c|c|c|}
\hline \multirow{3}{*}{$\kappa$} & \multicolumn{4}{|c|}{$\alpha$} & \multicolumn{4}{|c|}{$\beta$} \\
\hline & \multicolumn{4}{|c|}{$d / D$} & \multicolumn{4}{|c|}{$d / D$} \\
\hline & 0 & $0 \cdot 10$ & $0 \cdot 25$ & $0 \cdot 50$ & 0 & $0 \cdot 10$ & $0 \cdot 25$ & $0 \cdot 50$ \\
\hline $\begin{array}{r}0 \\
6 \\
20 \\
60 \\
100\end{array}$ & $\begin{array}{l}2 \cdot 13 \\
2 \cdot 58 \\
2 \cdot 83 \\
3 \cdot 32 \\
3 \cdot 74\end{array}$ & $\begin{array}{l}2 \cdot 33 \\
2 \cdot 09 \\
2 \cdot 47 \\
2 \cdot 51 \\
2 \cdot 56\end{array}$ & $\begin{array}{l}2 \cdot 33 \\
2 \cdot 10 \\
2 \cdot 01 \\
2 \cdot 10 \\
2 \cdot 12\end{array}$ & $\begin{array}{l}1 \cdot 46 \\
1 \cdot 76 \\
1 \cdot 83 \\
2 \cdot 19 \\
1 \cdot 90\end{array}$ & $\begin{array}{r}-0 \cdot 26 \\
-0 \cdot 11 \\
-0 \cdot 03 \\
0 \cdot 04 \\
0 \cdot 08\end{array}$ & $\begin{array}{l}-0 \cdot 28 \\
-0 \cdot 23 \\
-0 \cdot 15 \\
-0 \cdot 13 \\
-0 \cdot 12\end{array}$ & $\begin{array}{l}-0.49 \\
-0.35 \\
-0.29 \\
-0.29 \\
-0.27\end{array}$ & $\begin{array}{l}-0.57 \\
-0.55 \\
-0.55 \\
-0.51 \\
-0.48\end{array}$ \\
\hline
\end{tabular}

Table 8. Maximum values of $h_{\max } / h^{*}$ for low vertical load mobilisation $V / V_{\text {ult }} \leq 0 \cdot 50$

\begin{tabular}{l|c|c|c|c|c}
\hline \multirow{2}{*}{$d / D$} & \multicolumn{5}{|c}{$\kappa$} \\
\cline { 2 - 6 } & 0 & 6 & 20 & 60 & 100 \\
\hline 0 & 1 & 1 & 1 & 1 & 1 \\
$0 \cdot 10$ & $1 \cdot 01$ & 1 & 1 & 1 & 1 \\
$0 \cdot 25$ & $1 \cdot 09$ & $1 \cdot 01$ & $1 \cdot 01$ & $1 \cdot 10$ & $1 \cdot 10$ \\
$0 \cdot 50$ & $1 \cdot 34$ & $1 \cdot 15$ & & 1 & 1 \\
\hline
\end{tabular}




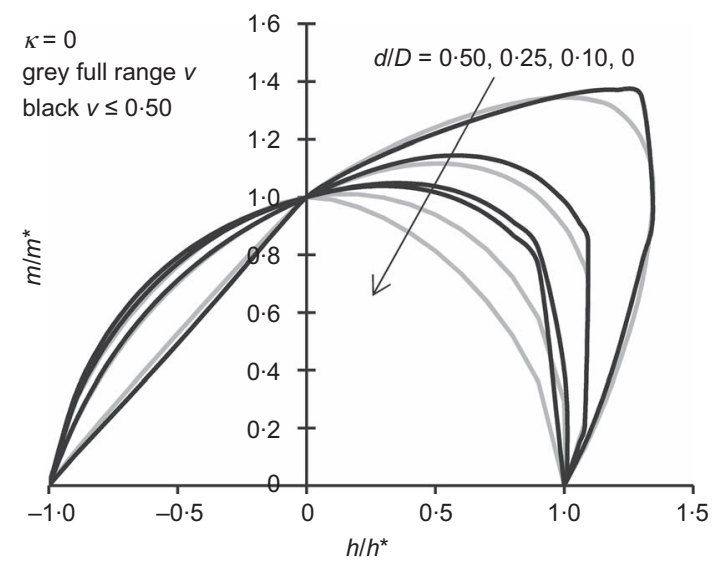

Fig. 8. Effect of vertical load mobilisation on available combined load capacity for full range of $v$ (grey lines) and $v<0.50$ (black lines)

from constant ratio displacement probes $(u / D \theta)$, as illustrated in Fig. 5. Once the failure envelope is reached, each load path travels around the envelope until it reaches a point where the normal to the failure envelope corresponds to the prescribed displacement ratio.

Figure 6 shows two dimensional slices in the HM plane through 3D VHM failure envelopes in dimensionless load space $\left(H / A s_{\mathrm{u} 0}, M / A D s_{\mathrm{u} 0}\right)$ at discrete levels of vertical load mobilisation $v=V I V_{\text {ult }}$. The failure envelopes in HM load space are seen to be asymmetrical about the $H$ and $M$ axes. The degree of asymmetry depends on the load combination, foundation embedment ratio and soil strength heterogeneity and has been observed both experimentally (Gottardi et al., 1999; Martin \& Houlsby, 2000; Zhang et al., 2014) and numerically (Ukritchon et al., 1998; Bransby \& Randolph, 1999; Martin \& Houlsby, 2001; Gourvenec \& Randolph, 2003; Gourvenec, 2008; Bransby \& Yun, 2009; Zhang et al., 2011).

The selections of FEA results presented in Fig. 6 demonstrate the effect on the size and shape of the failure envelopes with varying foundation embedment ratio (Fig. 6(a)), soil shear strength heterogeneity coefficient (Fig. 6(b)) and relative vertical load level (Fig. 6(c)). The results shown in Fig. 5 are consistent with the 60 sections of HM envelopes generated across the full range of foundation and soil conditions considered and are selected to illustrate the observed trends, avoiding the clutter of presentation of all results.

Embedment ratio and soil strength heterogeneity have the greatest influence on the shape of the failure envelopes (Figs 6(a) and 6(b), while the influence of the level of vertical load mobilisation is secondary (Fig. 6(c)). Increasing obliqueness of the failure envelopes (due to HM cross-coupling) is associated with increasing embedment ratio while asymmetry about the moment axis is associated with reducing soil strength heterogeneity. The level of vertical load has, by comparison, only secondary effects on the shape of the failure envelopes.

\section{APPROXIMATING EXPRESSION}

An approximating expression to predict the shape of the normalised VHM failure envelopes as a function of foundation embedment ratio and soil strength heterogeneity index can be defined by the elliptical expression

$$
\left(\left|\frac{h}{h^{*}}\right|\right)^{\alpha}+\left(\frac{m}{m^{*}}\right)^{\alpha}+2 \beta \frac{h m}{h^{*} m^{*}}=1
$$

in which $h=H / H_{\mathrm{ult}}$ and $m=M / M_{\mathrm{ult}}$ define the normalised horizontal load and moment mobilisation, while the effect

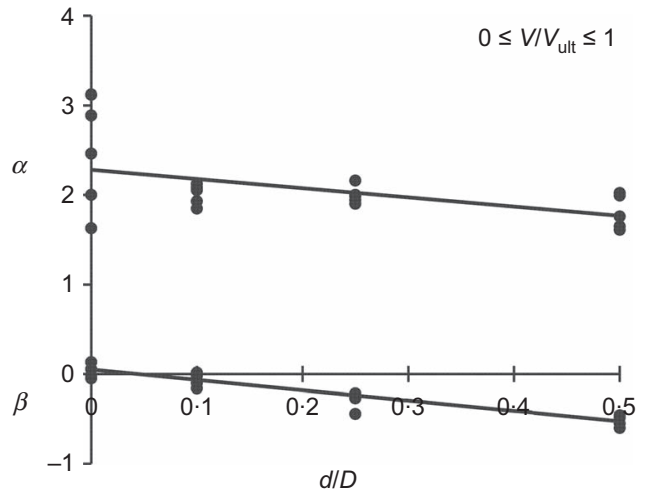

(a)

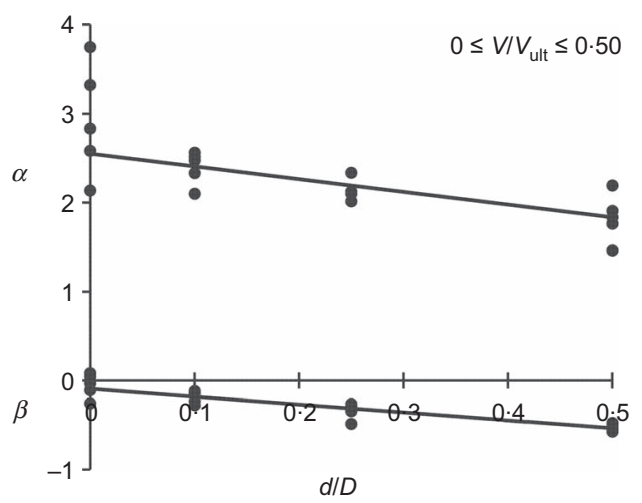

(b)

Fig. 9. Simplified fitting parameters $\alpha_{\mathrm{av}}$ and $\beta_{\mathrm{av}}$ (lines) and exact fitting parameters (symbols)

of vertical mobilisation, $v=V / V_{\text {ult }}$, is taken into account through $h^{*}$ and $m^{*}$ (equations (11) and (12)). $\alpha$ and $\beta$ are fitting parameters that depend on the foundation embedment ratio and soil shear strength heterogeneity index. In this case, the effect of the level of vertical load mobilisation is neglected in the prediction of the shape of the failure envelope (since the influence is considered secondary), but is incorporated in the prediction of the size of the failure envelope through $h^{*}$ and $m^{*}$. The form of equation (13) was proposed by Gourvenec \& Barnett (2011) for embedded strip foundations, but was defined as a function of embedment ratio only, since only low values of soil strength heterogeneity were considered in that case $(\kappa \leq 6)$ and therefore the effect was limited.

Figure 7 compares FEA results with the approximating expression in normalised $h^{*} m^{*}$ space for selected values of the foundation embedment ratio and soil strength heterogeneity index. The FEA capture the changing shape of the failure envelopes.

The fitting parameters $\alpha$ and $\beta$ are listed in Table 5 . Fitting parameters can be interpolated for intermediate values of the foundation embedment ratio and shear strength heterogeneity index. The values of $h_{\max } / h^{*}\left(h_{\max }\right.$ represents the maximum horizontal mobilisation as a result of HM cross-coupling) required to reconstruct the failure envelopes are given in Table 6.

The results presented in Fig. 7 indicate that the approximating expression becomes increasingly conservative for low vertical mobilisation $v=V / V_{\text {ult }}$ by neglecting the effect of vertical load level, but captures changes in shape associated with the foundation embedment ratio and soil strength heterogeneity. It should be borne in mind that predictions of ultimate limit states under combined loading 
Table 9. Summary of proposed procedure

\begin{tabular}{|c|c|c|}
\hline Step & Activity & Reference \\
\hline 1 & Evaluate $d / D, \mathrm{~s}_{\mathrm{u} 0}$ and $k D / s_{\mathrm{um}}$ for given foundation geometry and soil strength profile & \\
\hline 2 & Calculate $F_{\mathrm{v}}, d_{\mathrm{cV}}, N_{\mathrm{cV}}$ and $V_{\mathrm{ult}}$ & Equations (9), (3) and (6) \\
\hline 3 & Calculate vertical utilisation ratio $v=V / V_{\text {ult }}$ & - \\
\hline 4 & Calculate $h^{*}$ and $m^{*}$ & Equations (11) and (12) \\
\hline 5 & $\begin{array}{l}\text { Choose exact fitting parameters } \alpha \text { and } \beta \text { or calculate average fitting parameters } \alpha_{\mathrm{av}} \\
\text { and } \beta_{\mathrm{av}}\end{array}$ & Tables 5 and 7, Equations (14) and (15) \\
\hline 6 & Plot normalised $h^{*} m^{*}$ envelope for given $v$ (for constant intervals of $h$ solve for $m$ ) & - \\
\hline 7 & Calculate $N_{\mathrm{cH}}$ and $N_{\mathrm{cM}}$ (in absence of other loads or constraints) & Equations (10), (4), (5), (7) and (8) \\
\hline 8 & $\begin{array}{l}\text { Calculate } H^{*} / A s_{\mathrm{u} 0} \text { and } M^{*} / A D s_{\mathrm{u} 0} \text { at given vertical load level (i.e. } h^{*} \text { and } m^{*} \\
\text { multiplied by } N_{\mathrm{cH}} \text { and } N_{\mathrm{cM}} \text {, respectively) }\end{array}$ & - \\
\hline 9 & $\begin{array}{l}\text { Convert } h^{*} m^{*} \text { envelope to dimensionless load space (i.e. } h /\left(H^{*} / A s_{\mathrm{u} 0}\right) \text { and } m /\left(M^{*} /\right. \\
\left.\left.A D s_{\mathrm{u} 0}\right)\right)\end{array}$ & - \\
\hline
\end{tabular}

from the approximating expression proposed here are considerably less conservative than the predictions resulting from methods based on classical bearing capacity theory (demonstrated explicitly by Ukrtichon et al. (1998) and Gourvenec \& Barnett (2011)), which forms the basis of industry design guidance worldwide.

For cases in which vertical loads are known to be well below vertical capacity, optimised values of the fitting parameters $\alpha$ and $\beta$ were derived for low values of vertical load mobilisation. Optimised fitting parameters for vertical load mobilisation $v=V / V_{\text {ult }} \leq 0.50$ are presented in Table 7 , with the necessary values of $h_{\max } / h^{*}$ to reconstruct the envelopes given in Table 8 . Figure 8 illustrates the potential efficiency of accounting for limited vertical load mobilisation, showing larger normalised failure envelopes for the cases of limited vertical load mobilisation.

Simplified fitting parameters defined as a function of only the embedment ratio can be used to give a quick, rough indication of the failure envelope. For $0 \leq V / V_{\mathrm{ult}} \leq 1$, representative fitting parameters may be given by

$$
\begin{aligned}
& \alpha_{\mathrm{av}}=2 \cdot 28-1 \cdot 03(d / D) \\
& \beta_{\mathrm{av}}=0.05-1 \cdot 15(d / D)
\end{aligned}
$$

and for low vertical load mobilisation, $V / V_{\text {ult }} \leq 0 \cdot 50$, by

$$
\begin{aligned}
& \alpha_{\mathrm{av}}=2 \cdot 55-1 \cdot 43(d / D) \\
& \beta_{\mathrm{av}}=-0 \cdot 09-0 \cdot 88(d / D)
\end{aligned}
$$

Figures 9(a) and 9(b) show that $\alpha$ and $\beta$ are closely banded for each embedment ratio, except for the surface case, irrespective of soil strength heterogeneity and that the averaged expressions for $\alpha_{\mathrm{av}}$ and $\beta_{\mathrm{av}}$ (equations (14) and (15)) provide a satisfactory fit.

The procedure for recreating a failure envelope for a given foundation embedment ratio, soil strength heterogeneity index and vertical load mobilisation based on the method proposed in this paper is outlined in Table 9.

\section{CONCLUDING REMARKS}

This paper has presented undrained uniaxial ultimate limit states and failure envelopes for the VHM capacity of shallow circular foundations across a practical range of foundation embedment ratio and soil strength heterogeneity index. The shape of the normalised failure envelope is shown to vary with foundation embedment ratio and soil strength heterogeneity index and, to a lesser extent, with the level of vertical load mobilisation. A single algebraic expression was proposed to approximate failure envelopes as a function of embedment ratio and soil strength heterogeneity index. Fitting parameters for conditions of limited vertical load mobilisation were also proposed. Uniaxial bearing capacity factors were proposed through depth factors to transform normalised failure envelopes to absolute load space.

The tabulated data and fitting expressions proposed in the paper can be incorporated into a spreadsheet to

- enable automatic calculation of failure envelopes for selected foundation geometries and shear strength profiles

- optimise foundation geometry for a given set of design loads and shear strength profile

- evaluate load or material factors.

\section{ACKNOWLEDGEMENTS}

This work forms part of the activities of the Centre for Offshore Foundation Systems (COFS), currently supported as a node of the Australian Research Council Centre of Excellence for Geotechnical Science and Engineering. The work presented in this paper is supported through ARC grant (DP140100684), which is gratefully acknowledged.

\section{REFERENCES}

Bransby, M. F. \& Randolph, M. F. (1998). Combined loading of skirted foundations. Géotechnique 48, No. 5, 637-655.

Bransby, M. F. \& Randolph, M. F. (1999). The effect of embedment depth on the undrained response of skirted foundations to combined loading. Soils and Found. 39, No. 4, 19-33.

Bransby, M. F. \& Yun, G. J. (2009). The undrained capacity of skirted strip foundations under combined loading. Géotechnique 59, No. 2, 115-125.

Butterfield, R. \& Gottardi, G. (1994). A complete three dimensional failure envelope for shallow footings on sand. Géotechnique 44, No. 1, 181-184.

Butterfield, R. \& Ticof, J. (1979). Design parameters for granular soils (discussion contribution). Proc. 7th European Conf. Soil Mech. and Foundation Engng (ECSMFE), Brighton, 4, 259-261.

Butterfield, R., Houlsby, G. T. \& Gottardi, G. (1997). Standardised sign conventions and notation for generally loaded foundations. Géotechnique 47, No. 4, 1051-1052.

Cox, A. D., Eason, G. \& Hopkins, H. G. (1961). Axially symmetric plastic deformation in soils. Proc. Royal Soc. London, Ser. A 254, 1-45.

Dassault Systèmes (2012). Abaqus analysis user's manual. Providence, RI: Simulia Corp.

Feng, X., Randolph, M. F., Gourvenec, S. \& Wallerand, R. (2014). Design approach for rectangular mudmats under fully three dimensional loading, Géotechnique 64, No. 1, 51-63. 
Gottardi, G. \& Butterfield, R. (1993). On the bearing capacity of surface footings on sand under general planar load. Soils and Found. 33, No. 3, 68-79.

Gottardi, G., Houlsby, G. T. \& Butterfield, R. (1999). Plastic response of circular footings on sand under general planar loading. Géotechnique 49, No. 4, 453-469.

Gourvenec, S. (2007a). Failure envelopes for offshore shallow foundations under general loading. Géotechnique 57, No. 3, 715-728.

Gourvenec, S. (2007b). Shape effects on the capacity of rectangular footings under general loading. Géotechnique 57, No. 8, 637-646.

Gourvenec, S. (2008). Effect of embedment on the undrained capacity of shallow foundations under general loading. Géotechnique 58, No. 3, 177-185.

Gourvenec, S. \& Barnett, S. (2011). Undrained failure envelope for skirted foundations under general loading. Géotechnique 61, No. 3, 263-270.

Gourvenec, S. \& Mana, D. K. S. (2011). Undrained vertical bearing capacity factors for shallow foundations. Géotechnique Lett. 1 No. 4, 101-108.

Gourvenec, S. \& Randolph, M. F. (2003). Effect of strength nonhomogeneity on the shape and failure envelopes for combined loading of strip and circular foundations on clay. Géotechnique 53, No. 6, 575-586.

Govoni, L., Gourvenec, S. \& Gottardi, G. (2011). A centrifuge study on the effect of embedment on the drained response of shallow foundations under combined loading. Géotechnique 61, No. $12,1055-1068$.

Houlsby, G. T. \& Wroth, C. P. (1983). Calculation of stresses on shallow penetrometers and footings. Proc. IUTAMIIUGG Seabed Mechanics, Newcastle, 107-112.

Mana, D. K. S., Gourvenec, S. \& Martin, C. M. (2013). Critical skirt spacing for shallow foundations under general loading. ASCE J. Geotech. Geoenviron. Engng 139, No. 9, 1554-1566.

Martin, C. M. (2003). New software for rigorous bearing capacity calculations. Proc. Br. Geotech. Assoc. Int. Conf. on Foundations, Dundee, 581-592.

Martin, C. M. \& Houlsby, G. T. (2000). Combined loading of spudcan foundations on clay: laboratory tests. Géotechnique 50, No. 4, 325-338.
Martin, C. M. \& Houlsby, G. T. (2001). Combined loading of spudcan foundations on clay: numerical modelling. Géotechnique 51, No. 8, 687-699.

Martin, C. M. \& Randolph, M. F. (2001). Applications of the lower and upper bound theorems of plasticity to collapse of circular foundations. Proc. 10th Int. Conf. Int. Assoc. of Computer Methods and Advances in Geomech (IACMAG), Tucson 2, 1417-1428.

Meyerhof, G. G. (1953). The bearing capacity of foundations under eccentric and inclined loads. Proc. 3rd Int. Conf. on Soil Mechanics and Foundation Engng, Zurich, Switzerland, 1, 440-445.

Nova, R. \& Montrasio, L. (1991). Settlements of shallow foundations on sand. Géotechnique 41, No. 2, 243-256.

Randolph, M. F. \& Puzrin, A. M. (2003). Upper bound limit analysis of circular foundations on clay under general loading. Géotechnique 53, No. 9, 785-796.

Roscoe, K. H. \& Schofield, A. N. (1957). The stability of short pier foundations in sand: discussion. Br. Weld. J., January, 12-18.

Taiebat, H. A. \& Carter, J. P. (2000). Numerical studies of the bearing capacity of shallow foundations on cohesive soil subjected to combined loading. Géotechnique 50, No. 4, 409-418.

Taiebat, H. A. \& Carter, J. P. (2010). A failure surface for shallow circular footings on cohesive soils. Géotechnique 60, No. 4, $265-273$.

Ukritchon, B., Whittle, A. J. \& Sloan, S. W. (1998). Undrained limit analysis for combined loading of strip footings on clay. ASCE J. Geotech. Geoenviron. Engng 124, No. 3, 265-276.

Vulpe, C., Bienen, B. \& Gaudin, C. (2013). Predicting the undrained capacity of skirted spudcans under combined loading. Ocean Engng 74, 178-188.

Yun, G. \& Bransby, M. F. (2007). The horizontal-moment capacity of embedded foundations in undrained soil. Can. Geotech. J. 44, No. 4, 409-427.

Zhang, Y., Bienen, B., Cassidy, M.J. \& Gourvenec, S. (2011). The undrained bearing capacity of a spudcan foundation under combined loading in soft clay. Marine Struct. 24, No. 4, 459-477.

Zhang, Y., Bienen, B., \& Cassidy, M. J. (2014). A plasticity model for spudcan foundations in soft clay. Can. Geotech. J. 51, No. 6, 629-646, http://dx.doi.org/10.1139/cgj-2013-0269. 